
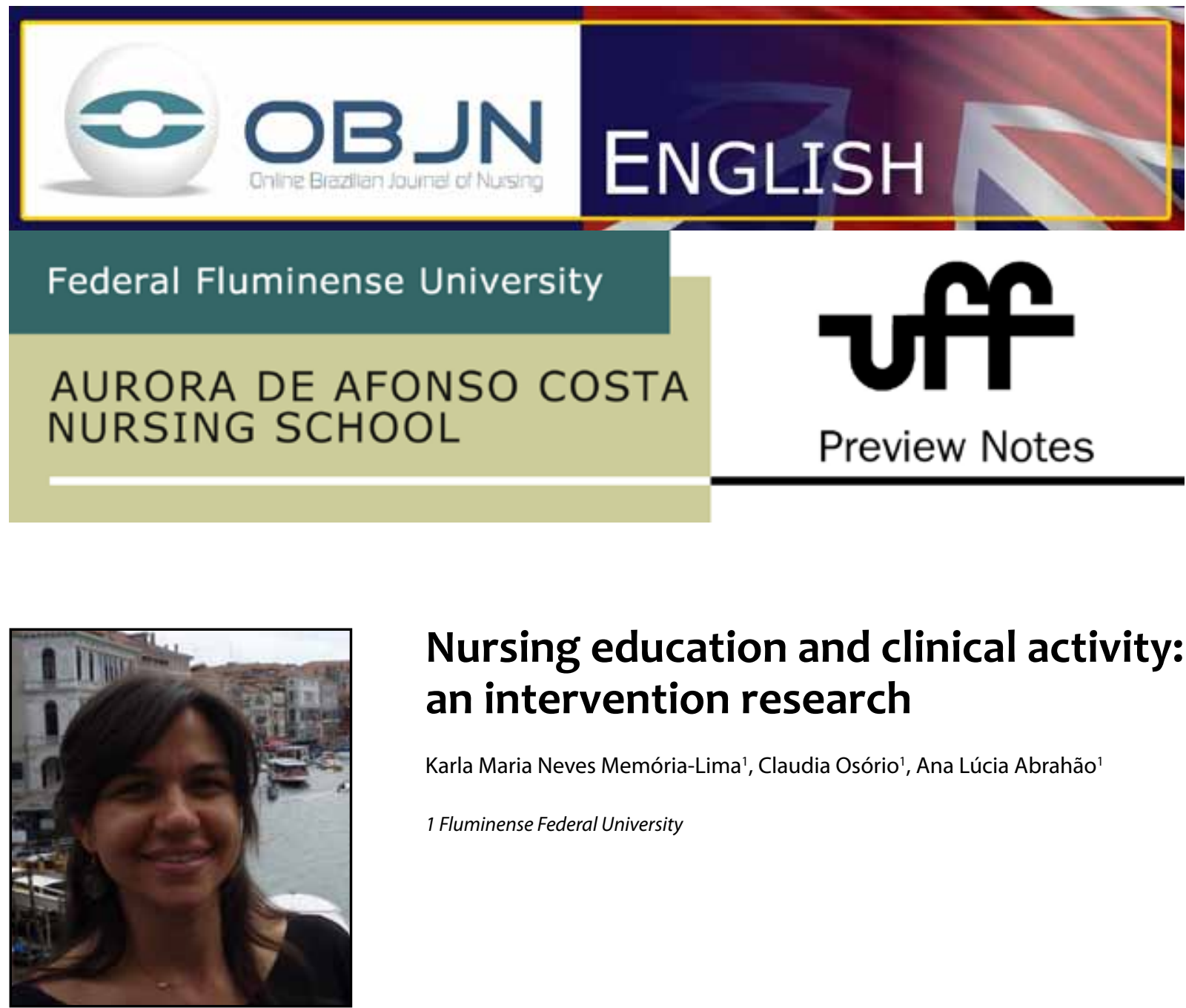

\title{
Nursing education and clinical activity: an intervention research
}

Karla Maria Neves Memória-Lima' ', Claudia Osório', Ana Lúcia Abrahão'

1 Fluminense Federal University

\section{ABSTRACT}

Aims: To investigate the training of nurses in a Public Federal University with the goal of promoting the enhancement of the education process. Problem: How to enrich the process of nurse training, taking into account the challenges and the features of the work involved? Method: a qualitative-approach research, along the lines of intervention research, using clinical activity as a reference. The research subjects are nursing students from a public university. Data will be collected through photo workshops, using the resources of phototypesetting and image intervention. The material will be analyzed following the clinical activity precepts that aim for the analysis of interviews. Data collection shall be carried out from January to December 2014.

Descriptors: Nursing; Health Education; Work; Public Health System. 


\section{THE SITUATION AND ITS SIGNIFICANCE}

In Brazil, there is an urge for finding new ways to enhance health care. This need has created different health care and political activities and changes in professional education in the area.

Since the 1980s, several strategies that prioritized action in terms of health promotion and disease prevention have been tested. Some of these experiences led, for example, to the creation of programs such as the Family Health Strategy (FHS) and to important changes in the training of professionals in order to meet the reality that is beyond the hospital walls. This new scenario requires nurses who are able to establish ways of working away from the medical environment. Working in patient home allows for greater understanding of the health-disease relationship and related forms of care. Furthermore, the work of health professionals in patients' home can produce unique circumstances for the workers themselves and for collective work, and transformations that impact on the social context in which they operate ${ }^{(1)}$.

Among the principles that guide this scenario, the overall focus highlights the social, cultural and economic aspects of the assisted population. For this to occur, the professionals must work in teams. This marks one of the critical points of the work: the difficulty of acting as a group, a fact that has been highlighted by a lack of skills when it comes to establishing constructive relationships between its members, since such skills are not fully developed by undergraduate courses in most professions.

A government policy to meet the new demands of training, the National Program for the Reorientation of Vocational Training in Health (the Pro-Health program) aims alter the training process, ensuring a more com- plete understanding of the health-disease relationship, with the aim of enhancing participants' knowledge thereby assisting the population. The Education Program at Work for Health (the PET-Health program) emerged as a part of the Pro-Health strategy with the aim of strengthening primary care, following the principles and requirements of the Public Health System, and is based on the concept of education through labor ${ }^{(1)}$.

These strategies are directed toward changes in the care and health management approach, and eventually towards changes in nursing education. The motivation for the development of this $\mathrm{PhD}$ project arose from the work of the researcher as a psychologist in a school of nursing, where it was possible to perceive the barriers experienced by students in terms of their training process.

\section{GUIDING QUESTIONS}

How can we go about enriching the training of nurses process, taking into account the challenges of the work involved? How can the aspects of creation in this training enrich the work activity? How can we enhance the training process and extend the action capabilities of nursing students?

\section{AIMS}

To investigate the training of nurses in a federal public university in the state of Rio de Janeiro, in order to promote the development of the training process; to produce knowledge about nursing education, focusing on the aspect of creativity, i.e., in seeking new ways to deal with the challenges of the future work in the training process. 


\section{METHOD}

This is a qualitative-approach research, following the lines of the intervention research approach. It is to be developed in a federal public nursing school in the state of Rio de Janeiro. All ethical aspects were respected in accordance with current law. For inclusion, the subjects should be federal public university students who integrate into teams in the public health system. Students under 18 years of age will be excluded. Interested students will be organized into a group of 8 to 12 participants, an adequate number to support the debate being raised. Data will be collected through photo workshop for four meetings between January and December 2014. This period is necessary for the preparation and post-execution of the workshop, as it will be held at different times of the year in various organizations in Brazil, such as hospitals, schools and public and private companies ${ }^{(2)}$.

This workshop, a method used in clinical activity, specifically uses the phototypesetting and picture edition approach. The photos are made by students and are considered trademarks of the training activity. They trigger the debate and reflection on the part of the group being studied. The data will be analyzed following Bakhtin's linguistic principles, in which we monitor dialogical movements in order to analyze the production of meanings. Workshop Step-by-step: recruitment of students; guidance for preparation of the photos; debate on the photos; restitution of research ${ }^{(2.3)}$.

\section{REFERENCES}

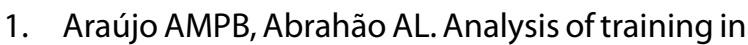
the health area: a map of curricular changes in education. Online Braz J Nurs [internet]. 2012 [ci- ted 2014 May 25];11(2):483-7. DOI: http://dx.doi. org/10.5935/1676-285.2012S016

2. Silva CO. A fotografia como uma marca do trabaIho: um método que convoca o protagonismo do trabalhador na invenção de mundos. In:Tittoni J, Zanela AV, organizadores. Imagens no pesquisar: experimentações. Porto Alegre: Dom Quixote; 2011. p. 211-226.

3. Clot Y. Trabalho e poder de agir. Belo Horizonte: Fabrefactum; 2010.

Project Data

Doctorate thesis project from the Post-Graduate Program in Psychology, at Fluminense Federal University. Approved by the Research Ethics Committee of the Antonio Pedro University-Hospital / UFF (HUAP / UFF), document ID number 447338 on November $1^{\text {st }} 2013$.

All authors participated in the phases of this publication in one or more of the following steps, in According to the recommendations of the International Committee of Medical Journal Editors (ICMJE, 2013): (a) substantial involvement in the planning or preparation of the manuscript or in the collection, analysis or interpretation of data; (b) preparation of the manuscript or conducting critical revision of intellectual content; (c) approval of the versión submitted of this manuscript. All authors declare for the appropriate purposes that the responsibilities related to all aspects of the manuscript submitted to OBJN are yours. They ensure that issues related to the accuracy or integrity of any part of the article were properly investigated and resolved. Therefore, they exempt the OBJN of any participation whatsoever in any imbroglios concerning the content under consideration. All authors declare that they have no conflict of interest of financial or personal nature concerning this manuscript which may influence the writing and/or interpretation of the findings. This statement has been digitally signed by all authors as recommended by the ICMJE, whose model is available in http://www. objnursing.uff.br/normas/DUDE_eng_13-06-2013.pdf

Received: 08/15/2014

Revised: 08/26/2014

Approved: 08/26/2014 